\title{
Vibração: fonte de incômodo à populaçao e de danos às edificações no meio urbano
}

\author{
Vibration: source of disturbance to the population and \\ damage to buildings in urban areas
}

\section{Luiz Antonio Brito \\ Álvaro Monoel de Souza Soares Bianca Nazari}

\section{Resumo}

Luiz Antonio Brito Programa de Pós-Graduação em Planejamento e Desenvolvimento Regional, Universidade de Taubaté, Rua Visconde do Rio Branco, 210, Centro, Taubaté-SP - Brasil CEP: $12020-040$ Tel.: (12) $3625-4151$ E-mail: labrito@bighost.com.br

Álvaro Manoel de Souza Soares Departamentos de Engenharia Mecânica e Informática Universidade de Taubaté Rua Daniel Danelli, s/n, Jardim Morumbi Taubaté - SP - Brasi CEP $12060-440$ Tel.: (12) 225-4260 E-mail: alvaro@unitau.br

Bianca Nazari Departamento de Arquitetura, Universidade de Taubaté, Praça Félix Guisard, 120 - Taubaté - SP - Brasil CEP: $12020-350$

Tel.: (12) 3625-4183

E-mail: bnazari@hotmail.com

Recebido em 03/07/10/12

Aceito em 06/03/13
A

energia vibratória gerada pelo tráfego de veículos leves e pesados e pelas composições ferroviárias são uma fonte de poluição ambiental pouco estudada no Brasil. A forma mais eficaz de atenuação da energia vibratória é o aumento da distância entre o receptor e a fonte, o que normalmente é obtido com os recuos definidos pelas leis de zoneamento urbano e pela faixa de domínio, tanto de ferrovias como de rodovias. $\mathrm{O}$ adensamento das áreas urbanas, já perceptível nas cidades de médio porte, gerado principalmente pela especulação imobiliária, vem aproximando as edificações das principais fontes de vibração no meio urbano. O efeito da energia vibratória nas edificações varia de acordo com o tipo de estrutura e fundação, sua altura e o tipo de solo. As construções que possuem estrutura em aço ou concreto armado tendem a receber melhor os efeitos da vibração (DIN 4150-3,1999). Em contrapartida, as construções antigas e patrimônios históricos, edificados com materiais menos resistentes, em algumas situações mal conservadas, podem sofrer desde trincas estéticas até danos estruturais irreversíveis quando expostas a elevados níveis de vibração. O objetivo deste trabalho é avaliar a incomodidade e os danos estruturais gerados pela energia vibratória induzida pelo tráfego rodoviário e ferroviário em edificações. Os resultados obtidos indicam que os limites de integridade estrutural são atendidos, mas não os de incomodidade.

Palavras-chave: Vibração. Poluição ambiental. Adensamento urbano.

\section{Abstract}

The vibratory energy generated by the traffic of light and heavy vehicles and trains is a source of environmental pollution barely studied in Brazil. The most effective way to lower vibratory energy to increase the distance between the receptor and the source, which is normally achieved through zoning laws and the width of the right-of-way of highways and railways. The densification of urban areas currently noticeable in medium-sizes cities, caused mainly by real-estate speculation, keeps bringing buildings near the main vibration sources in urban areas. The effect of vibratory energy on buildings varies according to their structure and foundations, their height and the soil-type. Buildings that have a steel or reinforced concrete structure tend to react better to the vibration effects (DIN 4150-3,1999). However, older constructions and historical sites, built with less resistant materials and, sometimes poorly preserved, can suffer not only aesthetical cracks but also irreversible structural damage when exposed to high levels of vibration. The aim of this study is to evaluate the discomfort and the structural damages that highways and railways cause on buildings. The results indicate that while the limits of structural integrity are not breached, those of discomfort are.

Keywords: Vibration. Environmental pollution. Urban densification. 


\section{Introdução}

O adensamento urbano, gerado principalmente pela especulação imobiliária, provoca o já conhecido efeito das ilhas de calor, que resulta em microclimas desconfortáveis à população, o que reduz a eficiência energética das edificações devido à necessidade de climatização artificial. Além deste e de outros efeitos encontrados na literatura nacional e internacional, há também a da incomodidade e possíveis danos estruturais ocasionados pela energia vibratória gerada no meio urbano. Essa causa de incômodo usualmente é atenuada pelo distanciamento entre a fonte e o receptor, sendo este definido nos planos diretores dos municípios e pela faixa de domínio de rodovias e ferrovias. $\mathrm{O}$ citado adensamento urbano provoca a redução desse recuo, a fim de aumentar a área ocupada dos terrenos, ou para a abertura e alargamento de ruas e avenidas, ou para a ocupação de faixas de domínio de antigas ferrovias, fato recorrente em várias cidades no Brasil, de modo que a principal forma de atenuação dos efeitos da vibração é reduzida ou definitivamente descartada.

A vibração induzida nas edificações pode gerar danos estruturais em algumas situações e apenas a incomodidade em outras. As construções que possuem estrutura em aço ou concreto armado tendem a receber melhor os efeitos da vibração (DIN 4150-3, 1999). Em contrapartida, as construções antigas e patrimônios históricos, edificados com materiais menos resistentes, como a alvenaria de tijolos de barro, queimados em fornos ou não, taipa ou madeira, podem sofrer desde trincas estéticas até danos estruturais irreversíveis quando expostas a elevados níveis de vibração. Deve-se também considerar nessa situação o estado de conservação das edificações. Além dos danos às edificações, também pode ocorrer a incomodidade dos usuários, já que a movimentação das janelas, por exemplo, causa incômodo devido ao ruído gerado, e a movimentação das lajes favorece o deslocamento de armários e até mesmo a abertura de algumas portas.

As principais fontes de vibração no meio urbano são o elevado tráfego de veículos pesados ou das composições ferroviárias que em muitas cidades atravessam áreas populosas, inclusive no período noturno. Estes podem gerar ondas vibratórias, que afetam as fundações das edificações. A vibração gerada pelo tráfego rodoviário é função da velocidade dos veículos, de seu peso e das condições do pavimento existente. A geração de energia vibratória aumenta quando há irregularidades na via, que amplificam o impacto das suspensões dos veículos, principalmente nos solos de baixo amortecimento (BRITISH..., 1990). Os pavimentos irregulares, como os prismáticos (paralelepípedos) à base de rochas ígneas (granitos), são os que geram mais energia vibratória, sendo a pavimentação asfáltica de boa qualidade uma medida mitigadora eficiente. As composições ferroviárias também são influenciadas pelos mesmos fatores do tráfego rodoviário, e a forma mais utilizada para reduzir o incômodo ou danos é a criação de faixas de domínios de pelo menos $30 \mathrm{~m}$ de largura (CHAVES et al., 2009). A energia vibratória artificial, oriunda das atividades urbanas, gera ondas na faixa de frequência entre $1 \mathrm{~Hz}$ e $150 \mathrm{~Hz}$ já nas fontes naturais de vibração a energia predomina entre $0,1 \mathrm{~Hz}$ e $30 \mathrm{~Hz}$, como os terremotos, e de $0,1 \mathrm{~Hz}$ a $2 \mathrm{~Hz}$ para o efeito da carga de vento em edifícios altos (INTERNATIONAL..., 1990).

A recepção da energia vibratória dá-se prioritariamente pelas fundações das edificações, que são as responsáveis por descarregar sua carga estrutural no solo e assim garantir a estabilidade. Dessa forma, pelo efeito inverso, as ondas vibratórias que eventualmente se propagam no solo induzirão um deslocamento na fundação, o qual, por sua vez, a transmitirá para a estrutura, para piso e paredes, e assim por diante. A resposta da edificação diante dessa excitação depende das frequências naturais da estrutura, seus modos de vibração e amortecimento (INTERNATIONAL..., 1990). O efeito acumulativo, ou seja, a energia vibratória gerada por diferentes fontes em diferentes frequências, pode reduzir a capacidade de amortecimento estrutural. Considera-se como parâmetro de análise da energia vibratória em uma edificação o pico de velocidade da partícula $(\mathrm{mm} / \mathrm{s})$, denominado PVP. As fundações pesadas atenuam a deformação das paredes devido à vibração induzida, de maneira que as trincas sejam mais comuns em edificações de estruturas leves. No caso de a estrutura ser rígida e apoiada em um solo de baixo amortecimento, o deslocamento nas paredes da edificação é praticamente nulo devido à resposta de corpo rígido da estrutura em frequências mais baixas, preservando as paredes de trincas. Para estruturas flexíveis apoiadas em solos rígidos, os deslocamentos na interface entre solo e estrutura, as fundações, são desprezíveis, mas as paredes deformam, acompanhando a movimentação do solo, o que resulta em trincas (FRANÇOIS et al., 2007). A faixa de frequência induzida pela onda vibratória que se propaga pelo solo na edificação também deve ser considerada nessa situação, já que os componentes da

130 Brito, L. A.; Soares, A. M. de S.; Nazari, B. 
edificação, como paredes, pisos e forros possuem frequências naturais maiores que as da estrutura, sendo mais influenciadas, principalmente, pela vibração contínua (fadiga), devido ao baixo amortecimento (BRITISH..., 1993). Caso a frequência de ressonância da estrutura da edificação seja similar à frequência de propagação da onda vibratória, haverá amplificação do deslocamento do solo/fundação, ocasionando um impacto indesejado. Para edificações de até $12 \mathrm{~m}$ de altura, por exemplo, o primeiro modo de vibração da estrutura fica na faixa de $4 \mathrm{~Hz}$ a $15 \mathrm{~Hz}$, e a energia vibratória gerada pelo tráfego rodoviário e ferroviário varia entre $1 \mathrm{~Hz}$ e $80 \mathrm{~Hz}$ (INTERNATIONAL..., 1990). Apenas em condições muito severas, como em solos não coesivos ou arenosos e siltosos de baixa resistência, é possível que haja o acoplamento das ondas vibratórias com as fundações de uma edificação (BRITISH..., 1993). Deve-se considerar também o efeito da fadiga da estrutura, que, em situações de baixo amortecimento e acoplamento estrutural, pode gerar danos mesmo com pequenas velocidades vibratórias. As frequências naturais de uma estrutura são dependentes de sua geometria, dos graus de liberdade das ligações, fundação e blocos, blocos e pilares, pilares e vigas, e assim por diante. Por exemplo, prédios antigos, pesados, com um pavimento, tendem a ter uma frequência natural maior que os leves, altos e flexíveis, como as edificações mais novas.

A propagação das ondas vibratórias no solo é influenciada por seu tipo e decaem principalmente com o aumento da distância, já que, desta forma, há um incremento de área na frente de onda, reduzindo a densidade energética (CHAVES et al., 2009). Esse processo pode ocasionar o adensamento do solo, principalmente os arenosos, com o risco de recalques diferenciais, aos quais até mesmo as estruturas e fundações mais sólidas não são capazes de resistir, podendo haver o rompimento. Nos solos mais rígidos a propagação da energia vibratória ocorre em maiores velocidades, então a tensão gerada nas fundações e, consequentemente, o PVP são inversamente proporcionais a esta, tanto para ondas de compressão quanto para as de cisalhamento. Dessa forma, em solos menos rígidos, onde a velocidade de propagação da energia vibratória é menor, as fundações poderão ter tensões similares às que são geradas em solos rígidos, mesmo com pequenos PVP (BRITISH..., 1993). A norma NP 2074 (NORMA..., 2004), Avaliação da influência em construções de vibrações provocadas por explosões ou solicitações similares, diferencia o PVP na estrutura da edificação para cada tipo de solo, além de categorizar a tipologia construtiva.
Para as edificações de estrutura convencional o PVP na estrutura pode variar de $5 \mathrm{~mm} / \mathrm{s}$, para solos arenosos e argilas moles, até $20 \mathrm{~mm} / \mathrm{s}$, para rochas e argilas duras. A diferença de velocidade das ondas vibratórias nos diferentes tipos de solos é devida principalmente à impedância elástica de cada um. Kirzhner, Rosenhouse e Zimmels (2006) pesquisaram esse efeito e concluíram que uma camada de solo arenoso compactado $(50 \mathrm{~cm})$ sobre uma camada de solo rígido, como argila dura ou solo rochoso, pode ocasionar uma atenuação da propagação na energia vibratória de até $35 \mathrm{~dB}$ na frequência de $100 \mathrm{~Hz}$. Concluíram ainda que o aumento da espessura da camada pouco altera o efeito, de modo que a diferença de impedância elástica do solo seja realmente o principal fator de redução da energia vibratória.

Os danos em edificações causados pela vibração devido ao adensamento urbano vêm sendo estudados nos últimos anos, principalmente na Europa, já que possui uma extensa malha ferroviária e grande número de edifícios antigos. Karantoni e Bouckovalas (1997) concluíram que os efeitos da vibração em casas de alvenaria são mais sistemáticos do que nos edifícios de concreto armado e que a idade dos materiais, os próprios materiais em si e o número de andares também influenciam no processo. Hunaidi (2000) mediu o nível de vibração gerada pelo tráfego de ônibus e caminhões, que diferem entre si devido ao sistema de amortecimento. Ele alega que fatores como a condição da rua, o peso, o sistema de amortecimento e a velocidade do veículo, o tipo do solo e sua estratificação, a época do ano, a distância da rua e o tipo de edificação são variáveis a ser consideradas quando se mede a vibração induzida pelo tráfego. A tendência da vibração oriunda de veículos pesados é a geração de ondas no solo entre $1 \mathrm{~Hz}$ e $80 \mathrm{~Hz}$ com uma velocidade da partícula de $0,2 \mathrm{~mm} / \mathrm{s}$ a $50 \mathrm{~mm} / \mathrm{s}$, dependendo do tipo e das condições da estrada, do peso e velocidade do veículo, e de seu sistema de amortecimento, sendo todos esses fatores independentes e difíceis de ser relacionados. Kim e Lee (2000) realizaram um estudo de várias fontes vibratórias, como o tráfego rodoviário e o ferroviário, bate-estacas, rolos compactadores vibratórios e detonação em minas, de modo a caracterizar as condições de propagação da energia vibratória em cada tipo de solo. Bacci et al. (2003) fizeram um levantamento das normas internacionais que contemplam a vibração em edificações e concluíram que a norma DIN 4150-3, Vibration in buildings, effect in structures (DEUTSCHES..., 1999), é a mais completa, sendo aceita por toda a comunidade europeia para análise de danos estruturais. François et al. (2007) 
utilizaram modelos tridimensionais para avaliar os efeitos da vibração induzida pelo tráfego em edificações de dois andares, de acordo com o tipo de solo, o modelo da edificação e sua distância até a avenida.

Os efeitos da vibração mecânica nas edificações podem ser divididos em dois tipos de análise. $\mathrm{O}$ primeiro tipo de análise quantifica os danos causados aos elementos estruturais e os estéticos como trincas nas paredes, ou alargamento das mesmas, e o escorregamento de telhas. $\mathrm{O}$ segundo quantifica a incomodidade gerada, seja pela vibração contínua, mesmo em baixas velocidades, seja pela aleatória.

A referência internacional para que se estudem os efeitos da vibração em estruturas é a norma DIN 4150-3 (DEUTSCHES..., 1999), Vibration in buildings, effect in structures. Esta separa as edificações em três categorias de análise, ou tipologias estruturais, em que especifica as frequências de análise e as velocidades máximas de deslocamento a que podem estar expostas. A Categoria 1 envolve edificações com estruturas de concreto armado e madeira em boas condições (mais resistentes); a Categoria 2 abrange edificações em alvenaria em boas condições; e a Categoria 3 refere-se a edificações de alvenaria em más condições de conservação, ou patrimônios históricos. O valor de pico de velocidade da partícula (PVP) para cada uma dessas classificações é dada pela Tabela 1. Essa norma também diferencia os níveis máximos por frequência, sendo consideradas três faixas: inferior a $10 \mathrm{~Hz}$; entre $10 \mathrm{~Hz}$ e $50 \mathrm{~Hz}$; e entre $50 \mathrm{~Hz}$ e 100 Hz. Acima deste valor a norma considera que não há risco de dano estrutural, pois as estruturas são mais resistentes.

Outra referência internacional é a norma ISO 4866 (INTERNATIONAL..., 1990), Mechanical vibration and shock - Vibration of buildings Guidelines for the measurement of vibration and evaluation of their effects on buildings. Esta classifica os danos causados pela vibração como aparentes, no caso de pequenas fissuras no reboco das paredes, de pequena monta no caso de trincas ou desprendimento do reboco das paredes, e de grande monta no caso de desprendimento de tijolos ou trincas na estrutura principal da edificação. As edificações geralmente possuem tensões residuais geradas pela acomodação natural do solo, pelos recalques diferenciais nas fundações, pela variação da umidade e temperatura, e pela falta de manutenção e conservação, fatores comuns nas cidades brasileiras. Assim, uma pequena velocidade induzida na estrutura pode acelerar esse processo de deterioração. Em alguns casos, quando uma edificação é submetida à vibração por muitos anos, a fadiga estrutural ocorrerá, sendo também causa de deterioração. Chaves et al. (2009), em sua pesquisa, por exemplo, verificaram que edificações sujeitas a velocidades inferiores ao normalizado apresentavam claros sinais de danos, devido à idade, acima de 60 anos em média, e pela ação das intempéries. A norma BS 7385-2 (BRITISH..., 1993), Evaluation and measurement for vibration in buildings - Part 2: Guide to demage levels from groundborne vibrations, complementa a ISO 4866 (INTERNATIONAL..., 1990) e estabelece limites de pico de velocidade da partícula para vibrações transientes, o que não considera o efeito da fadiga na estrutura. Nos casos de vibrações constantes com possibilidade de acoplamento estrutural, devese reduzir os valores da Tabela 2 em 50\%.

A vibração gerada por atividades rodoviárias, ferroviárias e industriais e transmitidas a seus ocupantes pode também ser abordada pelo critério de incomodidade. A norma ISO 2631-2 (INTERNATIONAL..., 2003), Mechanical vibration and shock - Evaluation of human exposure to whole-body vibration - Part 2: Vibration in buildings ( $1 \mathrm{~Hz}$ to $80 \mathrm{~Hz})$, aborda essa situação. A exposição à vibração nas faixas de frequências inferiores a $40 \mathrm{~Hz}$ são transmitidas a braços, mãos, ombro e cabeça, enquanto nas faixas acima de $100 \mathrm{~Hz}$, apenas as mãos são afetadas. A vibração pode ser intolerável para os ocupantes de uma edificação devido à sensação física de movimento, que interfere em algumas atividades como o sono, a conversação. Esta última, por exemplo, também será prejudicada pelo ruído gerado pela vibração de janelas e movimentação de objetos. Os limites de incomodidade para os ocupantes de uma edificação não são dados na versão de 2003 da referida norma, sendo, portanto, considerado o da versão de 1997, como ilustra a Tabela 3.

No Brasil não há uma normalização específica para o assunto, sendo a que mais se aproxima a norma NBR 9653 (ABNT, 2005), Guia para avaliação dos efeitos provocados pelo uso de explosivos nas minerações em áreas urbanas, que não aborda o assunto de maneira satisfatória no caso de vibração induzida pelo tráfego ferroviário e de veículos, sendo indicada para monitoramento da energia vibratória gerada pela detonação e desmonte de rochas. Outra referência pode ser a Decisão de Diretoria $\mathrm{n}^{\mathrm{o}}$ 215/2007/E, de 7 de novembro de 2007, da Cetesb, mas esta se restringe ao Estado de São Paulo e não distingue os tipos de estrutura analisadas, conforme dados da Tabela 4. Patrício (2001) fornece uma definição mais generalista do PVP, sendo a percepção humana de $0,3 \mathrm{~mm} / \mathrm{s}$; o desconforto de $1 \mathrm{~mm} / \mathrm{s}$; e danos estruturais de $10 \mathrm{~mm} / \mathrm{s}$. 
Tabela 1 - Limites de pico de velocidade da partícula (PVP) em mm/s segundo a norma DIN 4150-3 (1999) para integridade estrutural

\begin{tabular}{l|c|c|c|c}
\hline \multicolumn{1}{c|}{ Tipos de Edificação } & $\begin{array}{c}\boldsymbol{P V P} \\
(\mathbf{m m} / \mathbf{s}) \\
\text { Todas as } \\
\text { frequências }\end{array}$ & $\begin{array}{c}\boldsymbol{P V P} \\
(\mathbf{m m} / \mathbf{s}) \\
<\mathbf{1 0 ~ H z}\end{array}$ & $\begin{array}{c}\boldsymbol{P V P} \\
(\mathbf{m m} / \mathbf{s}) \\
\mathbf{1 0} \mathbf{~ a ~ 5 0 ~ H z ~}\end{array}$ & $\begin{array}{c}\boldsymbol{P V P} \\
(\mathbf{m m} / \mathbf{s})\end{array}$ \\
\hline $\begin{array}{l}\mathbf{5 0 ~ a ~ 1 0 0 ~ H z} \\
\text { Categoria 1, edificações de concreto armado } \\
\text { e de madeira em boas condições }\end{array}$ & 40 & 20 & 20 a 40 & 40 a 50 \\
\hline $\begin{array}{l}\text { Categoria 2, edificações de alvenaria em } \\
\text { boas condições }\end{array}$ & 15 & 5 & 5 a 15 & 15 a 20 \\
\hline $\begin{array}{l}\text { Categoria 3, edificações de alvenaria em más } \\
\text { condições de conservação e edificações } \\
\text { consideradas de patrimônio histórico }\end{array}$ & 8 & 3 & 3 a 8 & 8 a 10 \\
\hline
\end{tabular}

Tabela 2 - Limites de pico de velocidade da partícula (PVP) em mm/s segundo a norma BS 7385 -2 (1993) para integridade estrutural

\begin{tabular}{l|c|c}
\multicolumn{1}{c|}{ Tipos de Edificação } & $\begin{array}{c}P V P \\
(\mathrm{~mm} / \mathrm{s}) \\
4 \mathrm{a} \mathrm{15} \mathrm{Hz}\end{array}$ & $\begin{array}{c}P V P \\
(\mathrm{~mm} / \mathrm{s})\end{array}$ \\
\hline $\begin{array}{l}\text { Categoria 1 - Esturras reforçadas e pesadas de uso } \\
\text { comercial e industrial }\end{array}$ & 50 & 50 \\
\hline $\begin{array}{l}\text { Categoria 2, Estruturas frágeis e leves de uso } \\
\text { residencial e comercial }\end{array}$ & $15 \mathrm{a} 20$ & 20 a 40 \\
\hline
\end{tabular}

Tabela 3 - Limites do pico de velocidade da partícula (PVP) em mm/s da norma ISO 2631-2 (1997) para incomodidade

\begin{tabular}{c|c|c}
\hline Tipos de Edificação & $\begin{array}{c}\text { DIURNO } \\
\boldsymbol{P V P} \\
(\mathbf{m m} / \mathbf{s})\end{array}$ & $\begin{array}{c}\text { NOTURNO } \\
\text { PVP } \\
(\mathbf{m m} / \mathbf{s})\end{array}$ \\
\hline Hospitais & 0,10 & 0,10 \\
Residências & 0,40 & 0,14 \\
Escritórios & 0,40 & 0,40 \\
Oficinas & 0,80 & 0,80 \\
\hline
\end{tabular}

Tabela 4 - Limites de pico de velocidade da partícula (PVP) em mm/s segundo a Decisão de Diretoria $\mathrm{n}^{\circ}$ 215/2007/E, de 7 de novembro de 2007, da Cetesb

\begin{tabular}{c|c|c}
\hline Tipos de Áreas & $\begin{array}{c}\text { DIURNO } \\
\boldsymbol{P} \boldsymbol{V P} \\
(\mathbf{m m} / \mathbf{s})\end{array}$ & $\begin{array}{c}\text { NOTURNO } \\
\text { PVP } \\
(\mathbf{m m} / \mathbf{s})\end{array}$ \\
\hline Área de hospitais, casas de saúde ou escolas & 0,3 & 0,3 \\
Área de predomínio residencial & 0,3 & 0,3 \\
Área mista, com vocação comercial/e administrativa & 0,4 & 0,3 \\
Área predominantemente industrial & 0,5 & 0,5 \\
\hline
\end{tabular}

O objetivo deste trabalho é avaliar o impacto causado pela vibração induzida pelo tráfego ferroviário e de veículos em uma edificação, por meio da medição do pico de velocidade da partícula (PVP) e suas frequências dominantes.

\section{Método}

A edificação escolhida para as medições foi o Hospital Universitário de Taubaté, que está localizado no centro da cidade, entre as avenidas 9 e Julho, frente, e Prof. Luís Augusto da Silva, fundo. Paralelo à Av. Prof. Luís Augusto da Silva está o ramal da antiga Estrada de Ferro Central do Brasil, que liga as capitais dos Estados de São 
Paulo e Rio de Janeiro, que atualmente opera somente com transporte de carga. A Av. Prof. Luís Augusto da Silva foi recapeada e alargada em 2009 e ocupa parte da faixa de domínio da linha férrea. Esta era utilizada anteriormente apenas pelo tráfego local de veículos que se dirigiam a portaria de serviços do hospital e às poucas residências da via. Com as reformas, passou a fazer parte de um anel de circulação no centro da cidade de Taubaté, formando um binário com a Av. 9 de Julho, o que elevou o volume de tráfego, principalmente o pesado, que era quase inexistente, além do aumento da velocidade dos veículos. Nesta também há edificações antigas do início do século passado. A linha férrea lindeira à área de análise recebe composições ferroviárias de carga, principalmente de produtos siderúrgicos, como minério de ferro e aço, e cargas de cimento, tendo a frequência de passagem aumentado devido ao crescimento da indústria automobilista na região.

As medições foram realizadas no piso de acesso ao Hemocentro do Hospital. A Figura 1 ilustra a localização do Hospital Universitário (em branco), da Av. Prof. Luís Augusto da Silva (laranja), a 2 m do ponto de coleta, e da linha férrea (azul), a $15 \mathrm{~m}$ do ponto de coleta e da Av. 9 de Julho (amarelo). Dessa forma, é possível avaliar apenas o efeito do tráfego da Av. Prof. Luís Augusto da Silva e o ferroviário, já que as demais fontes urbanas estão afastadas devido à dimensão da área ocupada pelo Hospital. A Figura 2 ilustra a passagem de veículos leves e pesados pela via, e a Figura 3, a visada da composição ferroviária estacionada a partir do ponto de medição.

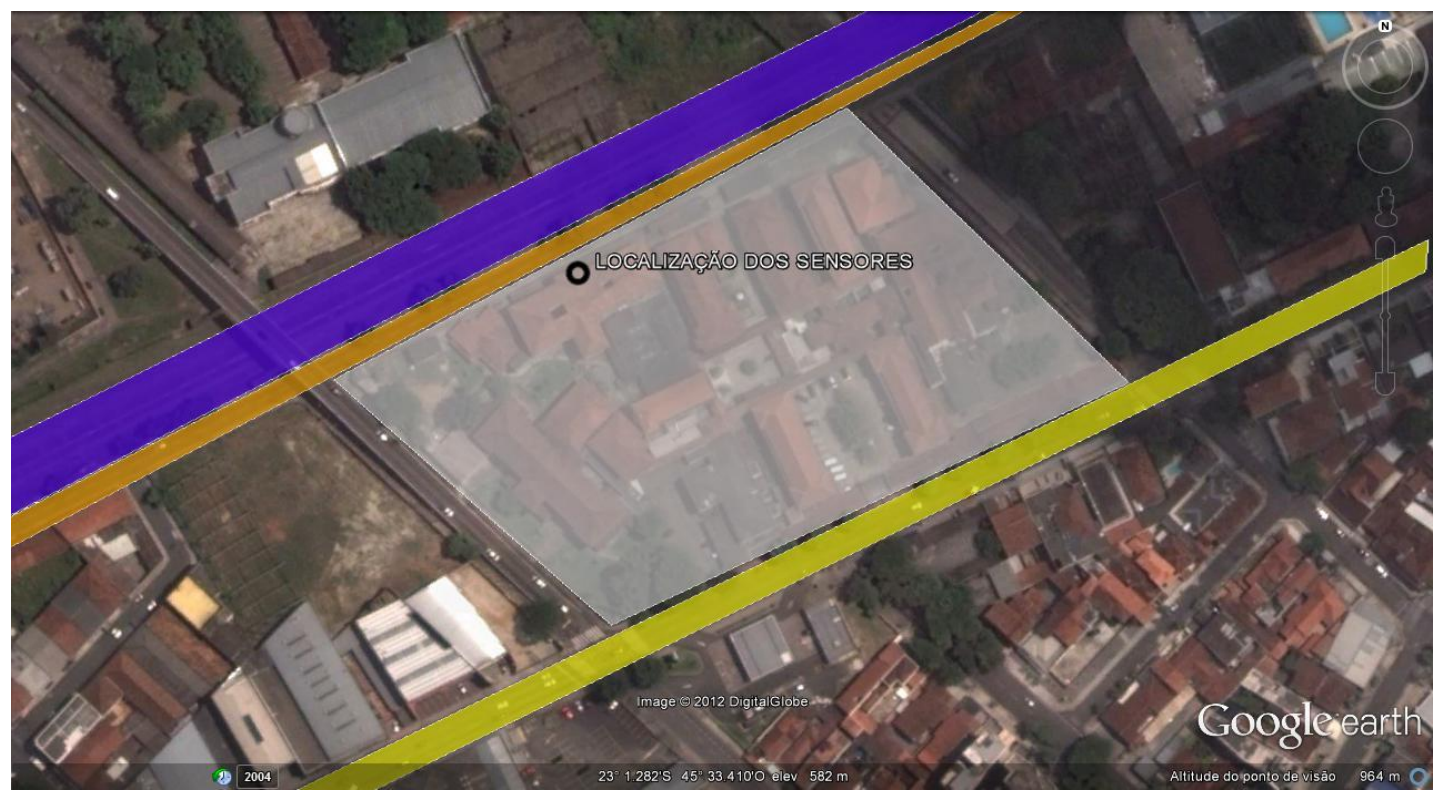

Figura 1 - Ilustração da localização do Hospital Universitário (em branco), da Av. Prof. Luís Augusto da Silva (laranja), da linha férrea (azul) e da Av. 9 de Julho (amarelo)

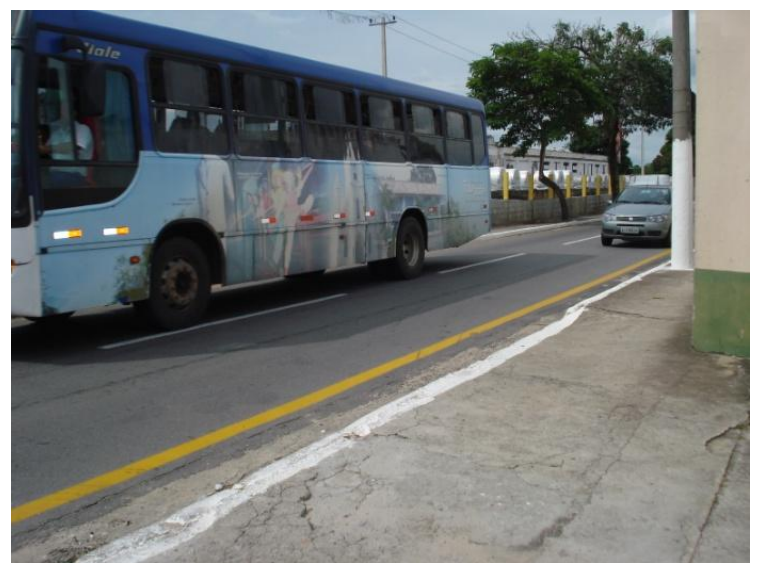

Figura 2 - Visada do tráfego de veículos pela Av. Prof. Luís Augusto da Silva a partir do ponto de medição

134 Brito, L. A.; Soares, A. M. de S.; Nazari, B. 


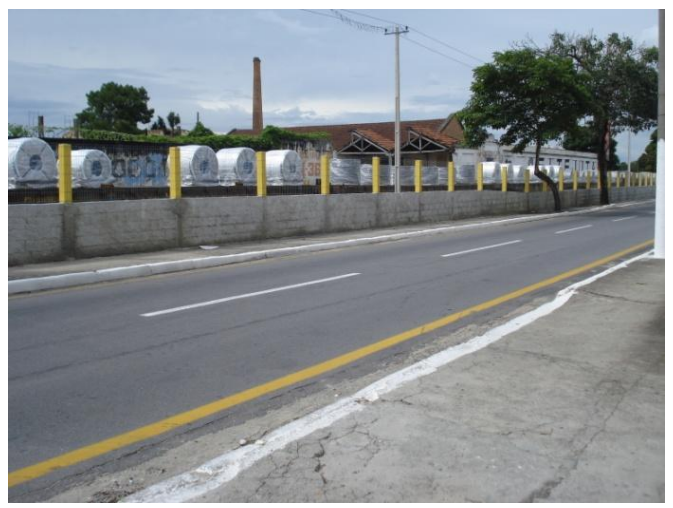

Figura 3 - Composição ferroviária estacionada próximo ao ponto de medição

O equipamento utilizado para a aquisição de dados foi composto de um acelerômetro capacitivo capaz de fazer leituras no eixo perpendicular ao plano horizontal (eixo z), conforme indicação da ISO 2631-1 (INTERNATIONAL..., 1987). O modelo do acelerômetro é MMA1220D Micromachined, da Motorola, conectado a uma placa de aquisição de sinais (NI USB-6009, da National Instruments), ligada a uma porta USB de um computador PC compatível. Para a aquisição dos dados experimentais foi desenvolvido um programa usando-se a linguagem gráfica de LabView®. O acelerômetro foi acoplado a um pod metálico com três apoios disposto no piso no local de acesso ao Hemocentro. Os três apoios do pod visam a um perfeito acoplamento entre o piso e o pod, de modo que toda a vibração seja transmitida ao acelerômetro para que o software transforme o sinal obtido no acelerômetro, aceleração, em velocidade, sendo considerado o pico de velocidade da partícula, PVP, conforme indicação das normas ISO 2631-2 (INTERNATIONAL..., 1987) e DIN 4150-3 (DEUTSCHES..., 1999). A aceleração RMS também foi obtida nas frequências entre $10 \mathrm{~Hz}$ e $100 \mathrm{~Hz}$ por meio da análise do sinal FFT (Fast Fourier Transform).

A confiabilidade do sistema foi testada montandose, em laboratório, um experimento, conforme ilustrado na Figura 4, consistindo de um shaker (ET-139 Electrodynamics Transducer, do LabWorks( ${ }^{\circledR)}$, sobre o qual foi acoplado o acelerômetro capacitivo (modelo MMA1220D Micromachined, da Motorola), utilizado neste trabalho, um acelerômetro piezoelétrico (modelo 353B18 da PCB Piezotronics) e um potenciômetro linear, responsável por medir o deslocamento da base do shaker. Após a aquisição dos dados, os sinais dos acelerômetros, que medem aceleração, foram integrados duas vezes, de forma a se obter o deslocamento, e comparados ao sinal do potenciômetro linear, a fím de validar as medidas realizadas. Os resultados obtidos estão ilustrados na Figura 5, para o acelerômetro capacitivo (A) e para o acelerômetro piezoelétrico (B). Durante o processo de integração foi utilizado um filtro passa-alta, com frequência de corte em $5 \mathrm{~Hz}$, conforme indicação de Lincoln (2007), para a melhoria da qualidade do sinal. A Figura 6 ilustra o sistema utilizado no momento da aquisição dos dados.

As medidas em campo foram executadas por um período de $90 \mathrm{~s}$, tempo de passagem da composição, divididas em 9 blocos de 10 s cada, sendo analisada uma composição vazia, três cheias, e por duas vezes apenas os veículos leves e pesados passando pela via. 


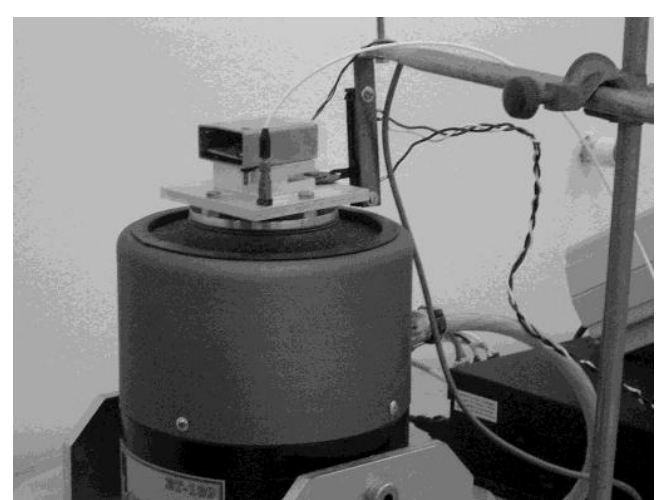

Figura 4 - Acelerômetros e potenciômetro acoplados ao shaker para calibração do sistema de medição

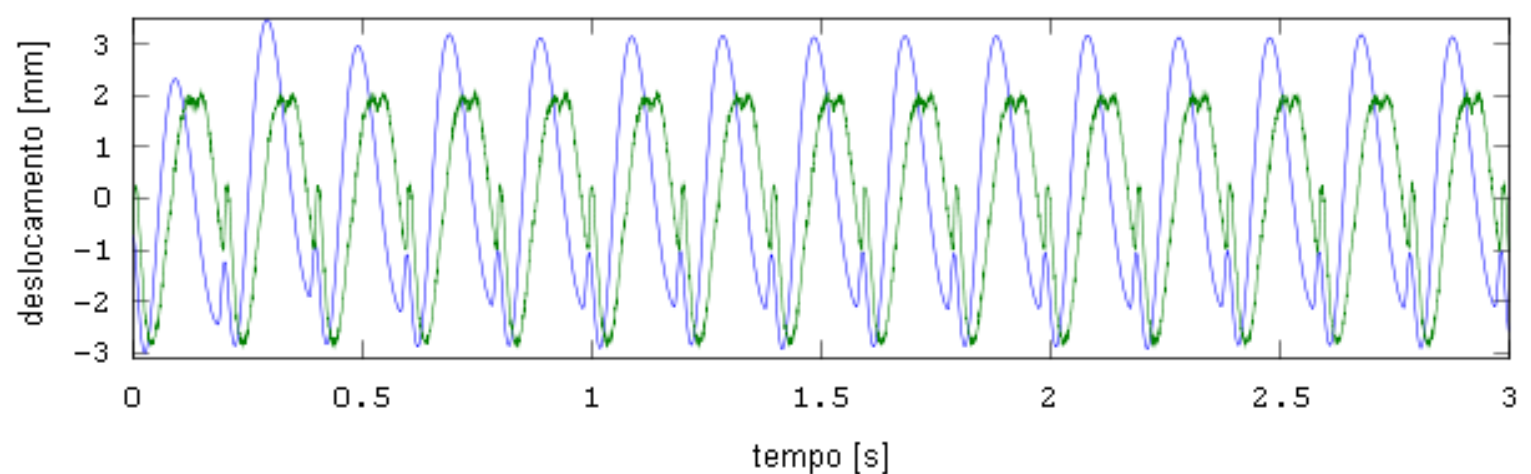

(a)

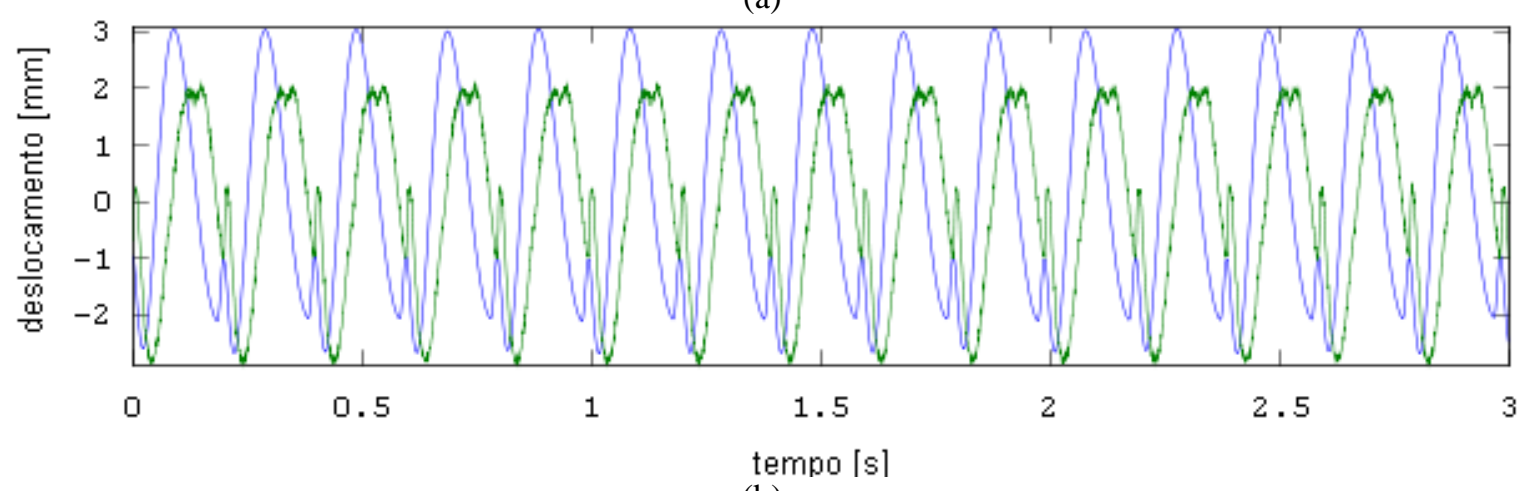

(b)

Figura 5 - Resultados obtidos durante o processo de calibração do acelerômetro capacitivo (a) e do acelerômetro piezoelétrico (b) em comparação com o potenciômetro (linha azul)

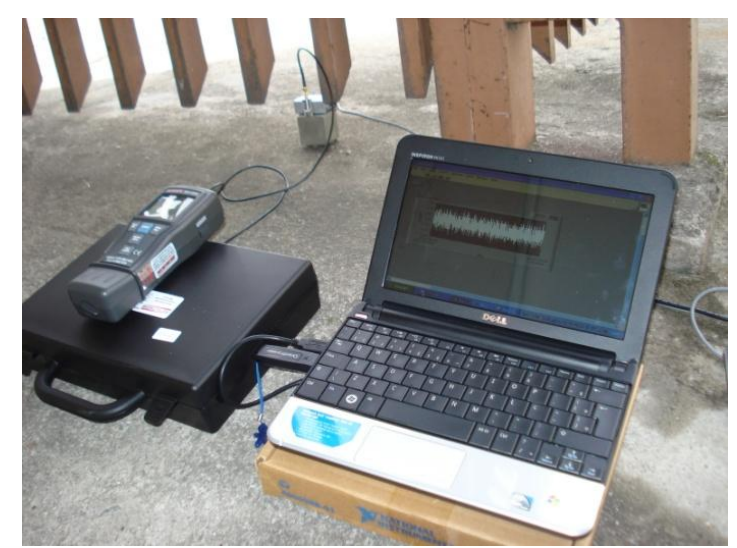

Figura 6 - Equipamento utilizado para aquisição de dados

136 Brito, L. A.; Soares, A. M. de S.; Nazari, B. 


\section{Análise dos resultados}

A Figura 7 ilustra o resultado obtido do PVP em $\mathrm{mm} / \mathrm{s}$ no eixo perpendicular ao plano horizontal, eixo $z$, devido à vibração induzida por uma composição vazia, três com carga, e por duas vezes apenas durante a passagem de veículos.

O PVP obtido no eixo perpendicular ao plano horizontal foi de $1,39 \mathrm{~mm} / \mathrm{s}$ devido ao tráfego de veículos e de $1,98 \mathrm{~mm} / \mathrm{s}$ devido à passagem de uma composição ferroviária carregada no momento de uma frenagem brusca. Esses valores satisfazem os requisitos da norma DIN 4150-3 (DEUTSCHES..., 1999) quanto à integridade estrutural da edificação, cujo limite para PVP em edificações antigas é de $8 \mathrm{~mm} / \mathrm{s}$. Quanto ao critério de incomodidade, os parâmetros da ISO 2631-2 (INTERNATIONAL..., 1997), cujo limite do PVP para hospitais é de $0,1 \mathrm{~mm} / \mathrm{s}$, são superados, bem como para os da Cetesb DD 215/2007/E (2007), cujos valores são de $0,3 \mathrm{~mm} / \mathrm{s}$ tanto no período diurno quanto no noturno.

Os resultados deste trabalho são compatíveis com os obtidos por outros pesquisadores, como, por exemplo, Watts e Krylov (2000), que obtiveram valores de PVP de $0,25 \mathrm{~mm} / \mathrm{s}$ a $6 \mathrm{~m}$ de distância de ruas com tráfego de veículos leves e pesados, inferior ao $1,39 \mathrm{~mm} / \mathrm{s}$ obtido a $2 \mathrm{~m}$ de distância. Neste caso, deve-se considerar a diferença de distância entre as duas situações, o que atenua a energia vibratória devido à grande capacidade de amortecimento do solo, já que este está compactado pelo tráfego de veículos na centenária avenida.

A norma BS 5228 - 4 (BRITISH..., 1996), Code of practice for noise and vibration control on construction and open sites vibration, fornece uma estimativa da velocidade induzida por várias atividades em função da distância, conforme os dados da Tabela 5. Esta estima que para o tráfego rodoviário o PVP deve ser em torno de $0,50 \mathrm{~mm} / \mathrm{s}$ a $2 \mathrm{~m}$ da via, sem especificar o tipo de via, nem os veículos que nela trafegam. Para o tráfego rodoviário em estradas pouco asfaltadas o PVP decai de 0,40 para $0,05 \mathrm{~mm} / \mathrm{s}$ em $4 \mathrm{~m}$ e $8 \mathrm{~m}$ de distância da via respectivamente, o que confirma a elevada capacidade de amortecimento de solos compactados para vias de tráfego.

Klaeboe et al. (2003) relacionaram a velocidade de vibração em edificações e o potencial de reclamações da população. Por exemplo, considerando os dados da Tabela 5, segundo esse pesquisador, a possibilidade de se notar a velocidade de vibração de $0,10 \mathrm{~mm} / \mathrm{s}$ (tráfego rodoviário a $4 \mathrm{~m}$ da edificação) é de $0 \%$, sendo essa velocidade exatamente o limite de incomodidade da norma ISO 2631-2 (INTERNATIONAL..., 1997). No caso de um veículo pesado a $4 \mathrm{~m}$ em uma rodovia asfaltada, com velocidade de $0,30 \mathrm{~mm} / \mathrm{s}$, a possibilidade de se notar a vibração é de $45 \%$, mas a chance de reclamação é inferior a 5\%, sendo essa velocidade o limite de incomodidade da Cetesb DD 215/2007/E (COMPANHIA..., 2007). A uma distância de $8 \mathrm{~m}$, com velocidade de $0,05 \mathrm{~mm} / \mathrm{s}$, a possibilidade de reclamação é inferior a $1 \%$. Assim, pode-se ver que os critérios internacionais são mais rigorosos que os poucos aqui existentes, já que o limite imposto pela única referência nacional poderia propiciar certo desconforto aos ocupantes. No caso de PVP em torno de $1,98 \mathrm{~mm} / \mathrm{s}$ gerado pela passagem da composição ferroviária, há uma probabilidade de $77 \%$ de as pessoas notarem a movimentação do piso e de $21 \%$ de notarem e se motivarem a fazer algum tipo de protesto ou reclamação. O PVP gerado pelo tráfego de veículos $1,39 \mathrm{~mm} / \mathrm{s}$ indica uma probabilidade de $71 \%$ de ser notado e de $14 \%$ de se motivar a reclamar. Deve-se destacar que esse é um estudo realizado na Noruega, onde os padrões de incomodidade da população são diferentes dos do Brasil.

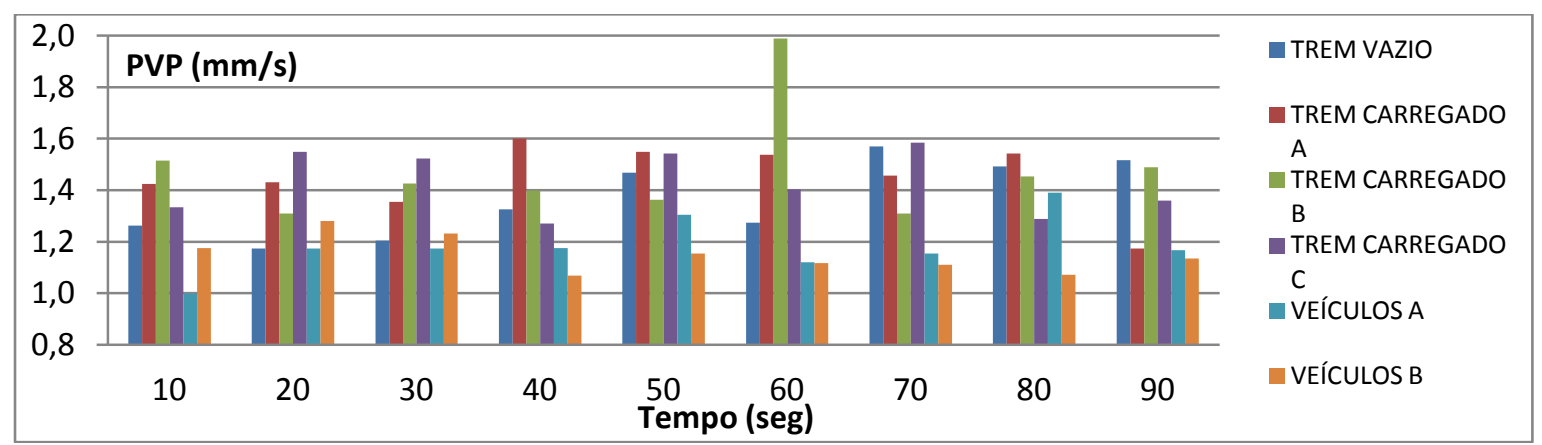

Figura 7 - Histórico no tempo do PVP (mm/s) no eixo perpendicular ao plano horizontal gerado pela passagem de uma composição férrea vazia, três carregadas, e veículos leves e pesados 
Tabela 5 - Ordem de grandeza, PVP, de algumas fontes de vibração em função da distância segundo a norma BS 5228-4 (BRITISH..., 1996)

\begin{tabular}{c|c|c}
\hline Atividade & Distância $(\mathbf{m})$ & PVP $(\mathbf{m m} / \mathbf{s})$ \\
\hline Tráfico rodoviário & 2 & 0,50 \\
Tráfico rodoviário & 4 & 0,10 \\
Veículo pesado em estrada pouco asfaltada & 4 & 0,40 \\
Veículo pesado em estrada pouco asfaltada & 8 & 0,05 \\
\hline
\end{tabular}

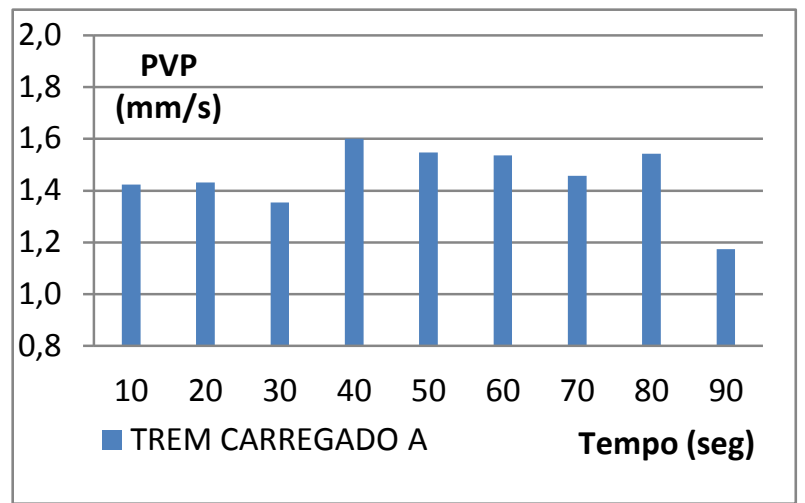

Figura 8 - Histórico do tempo do PVP no eixo perpendicular ao plano horizontal da composição A

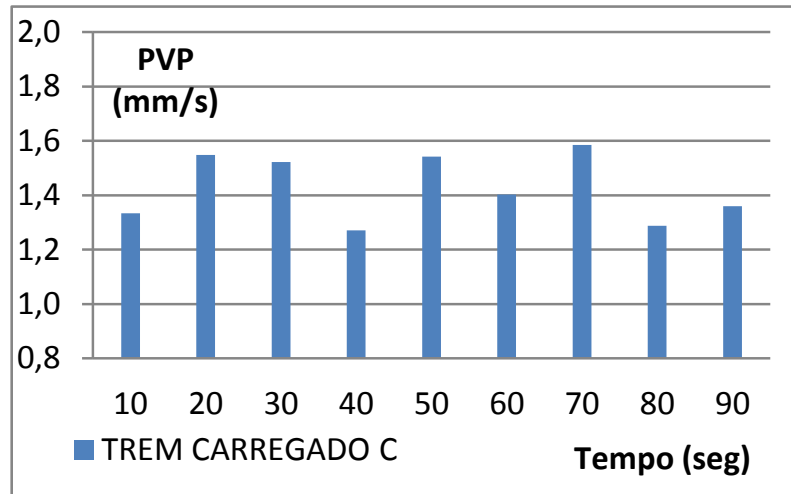

Figura 9 - Histórico do tempo do PVP no eixo perpendicular ao plano horizontal da composição C

Observando os dados do histórico do tempo das composições ferroviárias, pode-se observar que há um padrão de resultados de PVP no eixo perpendicular ao plano horizontal, sendo observado em todas as medições, mas que se destaca nas medidas A e C, conforme ilustram as Figuras 8 e 9 . O primeiro pico de PVP se dá no momento da passagem da locomotiva, cuja principal fonte de vibração é a rotação do motor, seguida de uma redução do PVP devido a seu afastamento. O segundo pico se dá na primeira frenagem da composição, seguido novamente de uma redução, e o terceiro pico, na segunda frenagem, de forma que, após este, há uma nova redução no PVP, pois a composição está praticamente estacionada.

As Figuras 10 e 11 ilustram os dados do FFT (Fast Fourier Transform) entre as frequências de $10 \mathrm{~Hz}$ e $100 \mathrm{~Hz}$. Pode-se observar que o sinal começa a se destacar a partir da frequência de $20 \mathrm{~Hz}$, sendo mais significativo entre $40 \mathrm{~Hz}$ e $60 \mathrm{~Hz}$, conforme a norma ISO 4866 (INTERNATIONAL..., 1990) prevê para esse tipo de fonte de energia vibratória. Segundo a mesma norma, edifícios baixos de até $12 \mathrm{~m}$, com cerca de 4 pavimentos, possuem baixa rigidez, pois não recebem cargas significativas de vento, e possuem uma frequência natural de vibração entre $4 \mathrm{~Hz}$ e $15 \mathrm{~Hz}$. Assim, não há o acoplamento entre os modos da frequência induzidos pela energia vibratória $(40 \mathrm{~Hz}$ a $60 \mathrm{~Hz}) \mathrm{e}$ os modos naturais das edificações (4 Hz a $15 \mathrm{~Hz}$ ), o que justifica a não existência de danos estruturais significativos; apenas o escorregamento de algumas telhas e trincas estéticas na alvenaria das edificações lindeiras à Av. Prof. Luís Augusto da Silva. Deve-se notar, neste caso, que a fadiga gerada, principalmente nas paredes, por longo

138 Brito, L. A.; Soares, A. M. de S.; Nazari, B. 
período de exposição à energia vibratória, acelera o processo de aparecimento de trincas estéticas, mesmo que o limite de integridade estrutural da norma DIN 4150-3 (DEUTSCHES..., 1999) seja atendido (CHAVES et al., 2009).

A norma ISO 2631-2 (1987) permite maiores valores de aceleração quanto maior for a frequência, a partir de $8 \mathrm{~Hz}$. Entre $40 \mathrm{~Hz}$ e $60 \mathrm{~Hz} \mathrm{o}$ limite de incomodidade fica na faixa de 4 a $5 \mathrm{~m} / \mathrm{s}^{2}$ para um período de exposição de $1 \mathrm{~min}$, estando a aceleração RMS obtida durante a passagem das composições B e C (Figuras 10 e 11) entre 10 e 15 $\mathrm{m} / \mathrm{s}^{2}$. Assim, tanto os resultados obtidos no parâmetro de pico de velocidade da partícula quanto em aceleração RMS superam os limites impostos pela normalização considerada neste estudo.

\section{Conclusões}

Os resultados obtidos foram coerentes com os encontrados na literatura e normalizações, nacional e internacional, de modo que o sistema de medição utilizado apresentou uma precisão adequada. A calibração do sistema bem como a utilização do filtro passa-alta ajudaram nesse processo.

O critério de danos estruturais da norma DIN 4150-3 (DEUTSCHES..., 1999) não foi superado, mesmo se considerando o limite para frequências inferiores de $10 \mathrm{~Hz}$. A frequência natural da edificação é inferior à frequência das ondas vibratórias das fontes analisadas, não havendo, portanto, o acoplamento delas, o que justifica a ausência de danos estruturais. Em distâncias menores, mesmo sem haver o acoplamento, essa situação pode se alterar. O efeito de outras fontes de vibração onde as frequências de excitação sejam inferiores a $10 \mathrm{~Hz}$, como um bate-estacas, por exemplo, pode gerar danos a esse tipo de edificação.

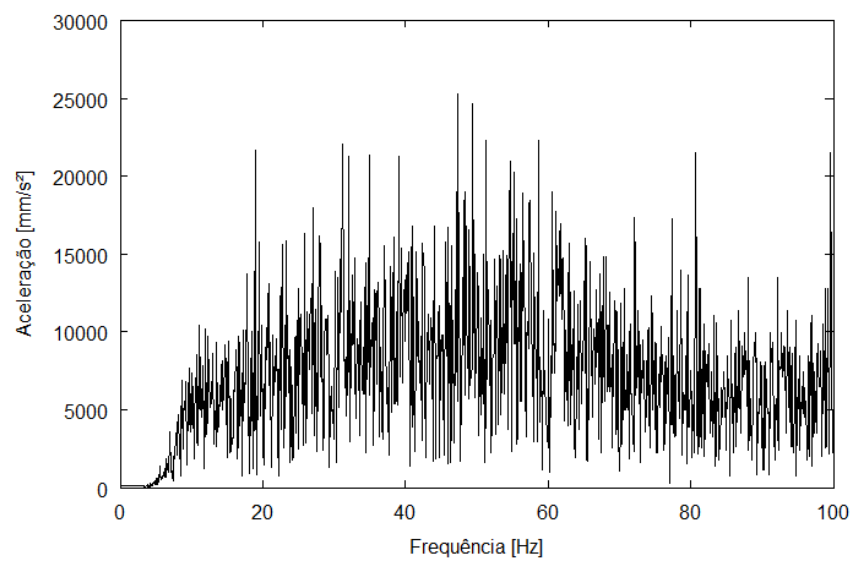

Figura 10 - Dados do FFT entre as frequências de $10 \mathrm{~Hz}$ e $100 \mathrm{~Hz}$ obtidos durante a passagem da composição B

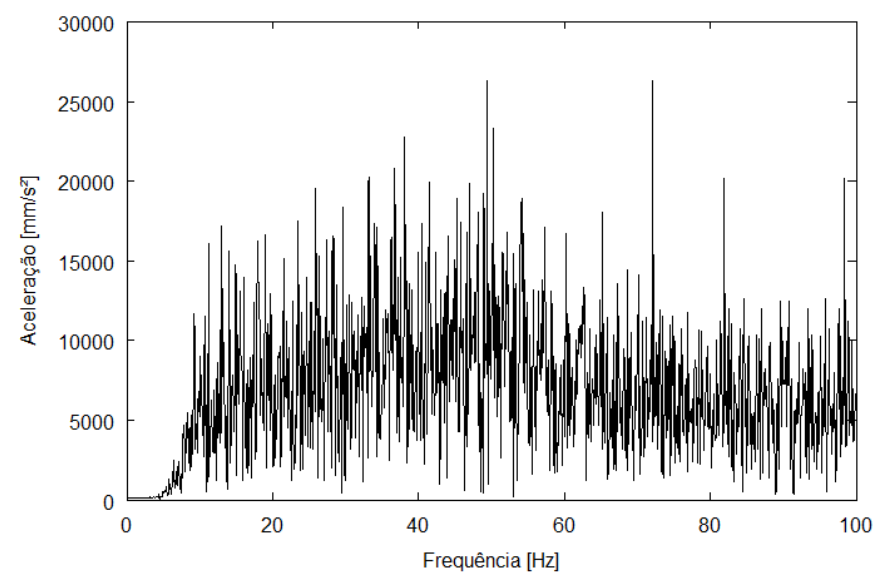

Figura 11 - Dados do FFT entre as frequências de $10 \mathrm{~Hz}$ e $100 \mathrm{~Hz}$ obtidos durante a passagem da composição C 
Os valores de pico de velocidade da partícula (PVP) obtidos mostram que o tráfego de veículos leves e pesados e o deslocamento da composição ferroviária geram ondas vibratórias que superam os critérios de incomodidade das normas ISO 2631-2 (INTERNATIONAL..., 1997) e Cetesb DD 215/2007/E (COMPANHIA..., 2007), sendo perceptíveis aos usuários do pavimento térreo do hospital, mas não o suficiente para motivar reclamações. A aceleração RMS, principalmente entre $40 \mathrm{~Hz}$ e $60 \mathrm{~Hz}$, também supera o limite de incomodidade imposto pela ISO 2631-2 (INTERNATIONAL..., 1997).

O histórico do tempo dos resultados obtidos da passagem da composição ferroviária demonstra um padrão de resultados, o que indica que a locomotiva é a principal fonte de vibração. A frenagem dela também eleva a energia vibratória, de modo que em situações críticas essa operação deve acontecer distante das edificações mais próximas.

A ocupação de parte da faixa de domínio da linha férrea para o alargamento da Av. Prof. Luís Augusto da Silva, sua utilização como parte do anel de circulação do centro da cidade e o aumento da quantidade de tonelagem das composições ferroviárias geram energia vibratória suficiente para causar incomodidade aos usuários do Hospital Universitário

Dessa forma, pode-se concluir que o tráfego de veículos leves e pesados pode gerar incomodidade aos usuários de uma edificação, assim como a passagem de uma composição ferroviária.

\section{Referências}

\section{ASSOCIAÇÃO BRASILEIRA DE NORMAS} TÉCNICAS. NBR 9653: guia para avaliação dos efeitos provocados pelo uso de explosivos nas minerações em áreas urbanas. Rio de Janeiro, 2005.

BACCI, D. L. C. et al. Principais Normas e Recomendações Existentes Para Controle de Vibrações Provocadas Pelo Uso de Explosivos em Áreas Urbanas: parte I. Revista Escola de Minas, V. 1, n. 56, p. 51-57, 2003.

BRITISH STANDARD. BS 7385-1: evaluation and measurement for vibration in building: part 1: guide for measurement of vibrations an evaluation of their effects on buildings. London, 1990.

BRITISH STANDARD. BS 7385-2: evaluation and measurement for vibration in building: part 2: guide to damage levels from ground borne vibration. London, 1993.
BRITISH STANDARD. BS 5228-4: code of practice for noise and vibration control on construction and open sites vibration. London, 1996.

CHAVES, G. V. A. et al. Faixa de Domínio e Sua Relação Com a Redução de Vibrações Produzidas Por Trens de Superfícies em Áreas Urbanas.

Revista Transportes, v. 17, n. 1, p. 39-45, 2009.

COMPANHIA DE TECNOLOGIA DE SANEAMENTO AMBIENTAL. Decisão de Diretoria n' 215/2007/E, 2007.

DEUTSCHES INSTITUT FUR NORMUNG. DIN 4150-3: vibration in buildings, effect in structures. Berlin, 1999.

FRANÇOIS, S. et al. The Influence of Dynamic Soil: structure interaction on traffic induced vibrations in buildings. Soil Dynamic And Earthquake Engineering, v. 27, n. 7, p. 655-674, 2007.

HUNAIDI, O. Traffic Vibrations in Buildings. Construction Technology Update, v. 39, 2000.

INTERNATIONAL ORGANIZATION FOR STANDARDIZATION. ISO 4866: mechanical vibration and shock: vibration of buildings: guidelines for the measurement of vibration and evaluation of their effects on buildings. Geneva, 1990.

INTERNATIONAL ORGANIZATION FOR STANDARDIZATION.ISO 2631-1: mechanical vibration and shock: evaluation of human exposure to whole-body vibration: part 1: general requirements (1 Hz to $80 \mathrm{~Hz}$ ). Geneva, 1997.

INTERNATIONAL ORGANIZATION FOR STANDARDIZATION.ISO 2631-2: mechanical vibration and shock: evaluation of human exposure to whole-body vibration: part 2: vibration in buildings (1 Hz to $80 \mathrm{~Hz}$ ). Geneva, 1997.

INTERNATIONAL ORGANIZATION FOR STANDARDIZATION. ISO 2631-2: mechanical vibration and shock: evaluation of human exposure to whole-body vibration: part 2: vibration in buildings (1 Hz to $80 \mathrm{~Hz}$ ). Geneva, 2003.

KARANTONI, F.; BOUCKOVALAS, G. Description and Analysis of Building Damage, Due to Pyrgos, Greece Earthquake. Soil Dynamics and Earthquake Engineering, v. 16, n. 2, p. 141150, 1997.

KIM, D. S.; LEE, J. S. Propagation and Attenuation Characteristics of Various Ground Vibrations. Soil Dynamics and Earthquake Engineering, v. 19, n. 2, p. 115-126, 2000. 
KIRZHNER, F.; ROSENHOUSE, G.; ZIMMELS, Y. Attenuation of Noise and Vibration Caused by Underground Trains, Using Soil Replacement. Tunneling and Underground Space Technology, v. 21 , n. 5, p. 561-567, 2006.

KLAEBOE, R. et al. Vibration in Dwellings From Road and Rail Traffic: part II: exposure-effect relationships based on ordinal logistic regression models, Applied Acoustics, v. 64, n. 1, p. 89-109, 2003.

LINCOLN, A. Calculating Velocity or Displacement From Acceleration Time Histories. 2007. Disponível em:

<www.prosig.com>. Acesso em: 12 nov. 2010.
NORMA PORTUGUESA NP 2074: avaliação da influência em construções de vibrações provocadas por explosões ou solicitações similares. Lisboa: Instituto Português da Qualidade (IPQ), 2004.

PATRICIO, J. Vibrações Ambientes: critérios de danos e de incomodidade: actualidade e perspectivas futuras. Tecni Acustica, La Rioja, Espanha, 2001.

WATTS, G. R.; KRYLOV, V. Ground Borne Vibration Generated By Vehicles Crossing Road Humps and Speed Control Cushions. Applied Acoustics, v. 59, n. 3, p. 221-236, 2000.

\section{Agradecimentos}

Os autores agradecem ao $\mathrm{CNPq}$ e à Universidade de Taubaté, pelo apoio e financiamento à pesquisa.

Revista Ambiente Construído

Associação Nacional de Tecnologia do Ambiente Construído

Av. Osvaldo Aranha, $99-3^{\circ}$ andar, Centro

Porto Alegre - RS - Brasil

CEP $90035-190$

Telefone: +55 (51) 3308-4084

Fax: +55 (51) 3308-4054

www.seer.ufrgs.br/ambienteconstruido

E-mail: ambienteconstruido@ufrgs.br 